\title{
Assessment of Nanocalcite Synthesis Routs on Green Biodiesel Production: Comparative Study
}

\author{
Salam A. Mohammed ${ }^{1, * \mathbb{D}}$, Hazim F Abbas ${ }^{1 \mathbb{D}}$, Hajer Alshihi ${ }^{2}$, Fazal Mabood ${ }^{3}{ }^{\mathbb{D}}$, Emad Yousif ${ }^{4} \mathbb{D}$, \\ Ali Abd Ali ${ }^{4}$ (D) , Zainab Hussain ${ }^{5}$, Khamis Al Riami ${ }^{2}$ \\ 1 Department of Chemical and Petrochemical Engineering, College of Engineering and Architecture, University of Nizwa, \\ Sultanate of Oman \\ 2 DARIS Research Centre, University of Nizwa, Sultanate of Oman \\ Department of Chemistry, College of Science, University of Nizwa, Oman \\ Department of Chemistry, College of Science, Al-Nahrain University, Baghdad, Iraq \\ Department of Chemistry, College of Science, Misan University, Misan, Iraq \\ * Correspondence: salam.mohammed@unizwa.edu.om;
}

Scopus Author ID 57189212521

Received: 24.03.2020; Revised: 28.04.2020; Accepted: 29.04.2020; Published: 3.05.2020

\begin{abstract}
There has been a large demand for producing and utilizing eco-friendly fuel during the past few decades. In this regard, proposing an alternative to fossil fuel has to be judged based on its availability, and sustainability. Biodiesel is one of the realistic candidates to be a fossil fuel substitute. Albeit, biodiesel production is not straight forward process as it involves a chemical reaction that necessitates the use of a catalyst. In current research, we synthesized calcite $\left(\mathrm{CaCO} / \mathrm{CaCO}_{3}\right)$ nanocatalysts were prepared using two common methods, namely, sol-gel and thermal method. The findings revealed that synthesized nanocatalyst by sol-gel method enhanced the biodiesel yield to $93 \%$ compare to $98 \%$ for nanocatalyst synthesized from egg shell by the thermal method. In a similar vein, the nanocatalysts manufactured by sol-gel and thermal methods were tested for their reusability and showed a $81 \%$, and $88 \%$, biodiesel yield respectively. Furthermore, the Cetane Index (CI) was measured to confirm the efficiency of the produced biodiesel which was within a recommended range of (45-54), suggestive that $\mathrm{CaCO} / \mathrm{CaCO}_{3}$ nanocatalyst might be a good candidate for efficient and reasonably clean biodiesel production from cooking oil waste.
\end{abstract}

Keywords: $\mathrm{CaO}$ nanocatalyst; biodiesel; thermal and sol-gel method; cooking oil; Egg shell.

(C) 2020 by the authors. This article is an open access article distributed under the terms and conditions of the Creative Commons Attribution (CC BY) license (https://creativecommons.org/licenses/by/4.0/).

\section{Introduction}

Generally, biodiesel refers to any diesel fuel alternative derived from renewable and biodegradable biomass. As a matter of fact, biodiesel is composed of esters of long chain fatty acids which can be obtained from vegetable oil, animal fat, and used cooking oil [1-3]. That fuel has accounted for sustainable alternative resources in comparison with petroleum based fuel supply due to the global usage demand [4]. That type of fuel has advantages in comparison with fossil diesel such as low or zero emission, non-toxic and essentially sulphur free making it environmentally friendly [5,6]. It has successfully been made from various resources, for instance, soybean [7], rapeseeds [8], Australian Native Stone Fruit Oil [9] and coconut [10]. There has been a significant advancement in the production and usage of biodiesel in many ways and in some diverse applications [11 -14].

Transesterification is one of the most efficient chemical reaction by which the vegetable oil or animal fat can be converted into a biodiesel $[15,16]$. Basically, the transesterification 
needs a catalyst to be achieved. Also, there might be some unfavorable side products which consequently effect on the biodiesel conversion efficiency $[1,17]$. To alleviate such problems, it has been widely endorsed that careful selection of a catalyst is very crucial in promoting biodiesel production efficiency [17-19].

In recent years, metal oxide nanomaterials have been suggested as catalysts due to their high surface area (higher population of active sites) [20], good catalytic activity, and efficient biodiesel production [21-25]. Wen Z. et al [26] used a mixture of titania and magnesium oxide nanomaterials to efficiently convert waste cooking oil into biodiesel. In a very recent study, Gurunathan B. et al [27] reported a 97\% biodiesel yield upon the usage of copper doped zinc oxide nanomaterials (CZO). Moreover, they reported almost $74 \%$ diesel yield by using a recycled $\mathrm{CZO}$ catalyst. In a similar work, Feyzi et al [28] used $\mathrm{Ca} / \mathrm{Fe}_{3} \mathrm{O}_{4}$ on $\mathrm{SiO}_{2}$ as a nanocatalyst in which they optimized the quantity of catalyst added to the reaction mixture to reach a biodiesel yield up to 97\%. Meanwhile, Boya Palajonnala Narasaiah and Badal Kumar Mandal [29] reported that $\mathrm{CuO}$ as nanomaterials exhibited as a suitable catalyst. Of late, nanocatalysts that prove better efficiency are being studied. Those nanoparticles are used in biological catalysts as solid transferors for lipase immobilization. Lipase immobilized on magnetic nanoparticles has proved to be a multipurpose biocatalyst for biodiesel production [30]

Calcium oxide $(\mathrm{CaO})$ is the most widely used as a solid basic catalyst due to many properties for example: long catalyst life, high activity, requires only moderate reaction conditions and providing high surface area-to volume ratio, environmentally friendly material, low synthesizing cost, and a large number of basic sites. In addition, $\mathrm{CaO}$ has attracted much attention due to the fact that there are several natural calcium sources from wastes, such as egg shells or mollusk shells. These shells are composed of calcium carbonates that are calcined in order to produce basic calcium oxide that can be used as a catalyst for the production of biodiesel [31].

Thermal decomposition and sol-gel methods are among major methods that have been used to prepare nano $\mathrm{CaO}$. It was reported that calcinations temperature plays a dominant rule in thermal decomposition due to its influence on desorption of molecules and readjustment of atoms on particle external surface. The sol-gel method is a wet-chemical technique used for nano $\mathrm{CaO}$ preparation. It is simple, cheap, not time consuming and no expensive equipment is required. It can also be carried out at a lower temperature and with no pressure. Therefore, it can be a promising method to synthesize $\mathrm{CaO}$ nanoparticles [32].

In this article, calcite nanomaterials were synthesized and used as a nanocatalyst for transesterification reaction to convert used cooking oil to a biodiesel. Moreover, this study presents very useful information with respect to comparing characteristic and conversion efficiency of the produced nanocatalyst which was synthesized from two different protocols, namely, sol-gel and thermal method.

\section{Materials and Methods}

\subsection{Materials and method.}

All chemicals $\left(\mathrm{Ca}\left(\mathrm{NO}_{2}\right)_{2}\right.$, cetric acid were sourced from Sigma Aldrich and were used without further purification. 


\subsection{Calcite nanomaterial synthesis.}

\subsubsection{Sol-Gel Method.}

A $4.77 \mathrm{~g}$ of $\mathrm{Ca}\left(\mathrm{NO}_{3}\right)_{2}$ was dissolved in $20 \mathrm{~mL}$ water and then added to $19.30 \mathrm{~g}$ citric acid dissolved in $20 \mathrm{~mL}$ water. The reaction mixture then was allowed to evaporate at $60^{\circ} \mathrm{C}$ until overnight. The resulting powder then calcined at $600^{\circ} \mathrm{C}$ for 4 hours.

\subsubsection{Thermal Method.}

Ordinary Eggshells were washed with water repeatedly to remove any impurities and then dried in hot air oven at $110 \mathrm{oC}$ for about 24 hours. The dried shells were finely grinded, then sieved to obtain uniform size of the powder. The powder then was placed in a muffle furnace at 600 and other sample at $900^{\circ} \mathrm{C}$ for 5 hours.

\subsection{Transesterification process.}

A $0.4 \mathrm{gm}$ of formed calcite nanocatalyst and $250 \mathrm{~mL}$ of ethanol were placed into a 1000 $\mathrm{mL}$ round bottom flask. The mixture was then refluxed at $60^{\circ} \mathrm{C}$ for 1 hour with stirring at 600 rpm to have a homogenous mixture. After cooling the flask with ice to room temperature, 150 $\mathrm{ml}$ waste cooking oil was added to the mixture (3:5 oil to ethanol ratio) and final media refluxed again at $60^{\circ} \mathrm{C}$ for 3 hours at $600 \mathrm{rpm}$. To prevent evaporation of methanol during the reaction, a water-cooled condenser was used.

When the reaction completed, the mixture was cooled to a room temperature. The produced mixture was kept overnight to enhance separation by gravity to different layers. Three distinct liquid phases were formed during separation such that crude ester phase at the top, glycerol phase at the middle and part of nanocatalyst at the bottom. The yield based on formed methyl ester (biodiesel) to the original quantity of limited reactant (cooking oil) was estimated.

The aforementioned procedure for transesterification reaction was repeated using catalyst generated by sol-gel method and the second calcite nanocatalyst that prepared using thermal method at 600 and $900^{\circ} \mathrm{C}$.

\subsection{Biodiesel assessment.}

\subsubsection{Gas Chromatography- Mass Spectrometry (GC-MS).}

To identify quality of produced biodiesel, GC-MS analysis was conducted using HP 6890 gas chromatograph coupled with HP 5973 Mass Selective Detector (Agilent Technologies, Foster City, CA, USA). Helium was used as a carrier gas at a flow rate of 64 $\mathrm{mL} / \mathrm{min}$ to carry $2 \mu \mathrm{L}$ of the sample through $30 \mathrm{~m}$ of silica capillary column. The mass spectrometer was working based on electron impact in the scan range of $50-650 \mathrm{~m} / \mathrm{z}$ and a software was used for data acquisition to identify peaks.

\subsubsection{Near Infra-Red (NIR) Measurements.}

Standard samples of diesel from crude oil base were collected from the Oman Oil Refineries, Shell and Al Maha Refineries were mixed with dichloromethane at the following percentage levels: $0.1,0.5,1,5,7,10,13,15,17,20,25,30,35$ and $40 \%$. Analysis of each sample was repeated three times to improve the reliability of the results. The usage of 1 st 
derivative functions with Savitzky-Golay smoothing to the spectra improved the accuracy of PLS models built through parameters like RMSEC, RMSEP and $\mathrm{R}^{2}$.

\subsection{Catalyst characterization SEA, XRD.}

X-ray diffraction (XRD) analysis using a MiniFlex600 benchtop X-ray diffractometer with graphite monochromatized $\mathrm{Cu} \mathrm{K \alpha}$ radiation $(\lambda=1.540 \AA)$ ) source was used to study.

\subsection{Cetane number $(C N)$ measurement.}

The $\mathrm{CN}$ for the biodiesel produced was measured using an octane meter of SX-200 portable octane tester. This meter can measure the $\mathrm{CN}$ within the range 20-100. CNs measurement was done according to the ASTM D 4737-03, ASTM D 613, EN ISO 5165.

Each sample was transferred into the meter detector and then measured the $\mathrm{CN}$ and record the value appeared on the screen. Cns measurement was thrice repeated and the average value was calculated. We were testing the temperature of the sample before pouring it into the meter detector. The room temperature was $~ 20$ degrees, and all solutions were allowed to be within the room temperature as well. After testing every sample, the detector was emptied and wiped with a clean tissue prior to introducing the next sample.

\section{Results and Discussion}

\subsection{Catalyst characterization.}

\subsubsection{SEM, TEM and EDS.}

The nanocatalyst was initially characterized by Scanning Electron Microscopy (SEM), and Transition Electron Microscopy (TEM) techniques. The SEM images showed very porous nanomaterials with high surface volume. As a result, we observed a large aggregation of calcite nanomaterials as shown in Figure 1 A, B, C, and D.

To further identify the calcite synthesized by both methods, energy dispersive spectroscopy (EDS) conducted to give some quantitative information of the catalyst synthesized. In both methods, Ca showed two overlapped peaks $(\sim 4 \mathrm{k} \mathrm{eV}$, and one peak at $0.5 \mathrm{k} \mathrm{eV}$ ) which indicated oxygen as depicted in Figure $1 \mathrm{E}$, and F. Interestingly, there was another peak $(\sim 0.2-0.3 \mathrm{k} \mathrm{eV})$ attributed to carbon atom.

\subsubsection{XRD catalyst characterization.}

The crystal phases of the two best samples (sol-gel at $600^{\circ} \mathrm{C}$ and thermal at $900^{\circ} \mathrm{C}$ ) were observed via the X-ray diffraction (XRD) analysis. The results for XRD pattern for the tested samples are presented in Figure 2. Figure 2A shows very nice sharp intensity at five peaks which it is agreed with other researches finding (Risfidian Mohadi et. Al. 2016) and the conducted measurement observes forming $\mathrm{CaCO} / \mathrm{CaCO}_{3}$ with grain size of $80.23 \mathrm{~nm}$. In other hand, figure $2 \mathrm{~B}$, which reveals sharp morphology for the nano powders with a mixture of two components $\mathrm{CaCO} / \mathrm{Ca}(\mathrm{OH})_{2}$ and grain sizes of 59.64 and $14.83 \mathrm{~nm}$ respectively.

\subsubsection{Gas Chromatography-Mass Spectrometry.}

GC-MS was used to identify biodiesel methyl ester groups present in a sample of biodiesel produced using 3:5 ratio and eggshell nanocatalyst calcined at $900^{\circ} \mathrm{C}$ and the results 
are shown in Figure (3). It is seen from Figure (3) that four major characteristic peaks of fatty acid methyl esters (FAMEs) identified by the retention time and the fragmentation pattern data of GC-MS analysis. The identified four peaks are, methyl ester Palmitic acid ME C16:1 (16.62\%), 9,12-Octadecadienoic acid C18:2 (10\%), Stearic acid C18:0 (6.87\%) and C18:3 $\gamma$ Linolenic acid methyl ester (2.31\%).

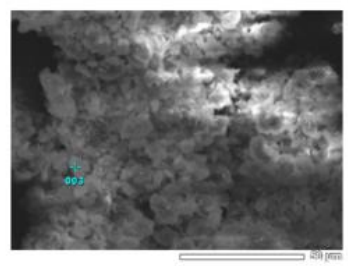

(a)

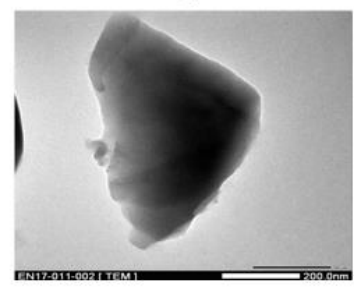

(c)

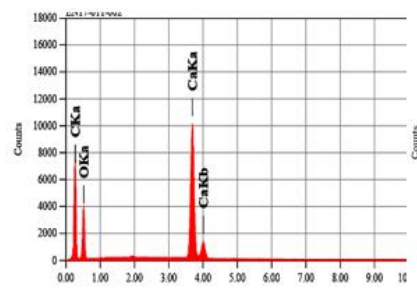

(e)

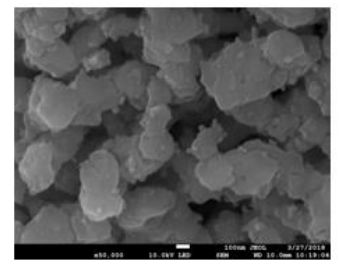

(b)

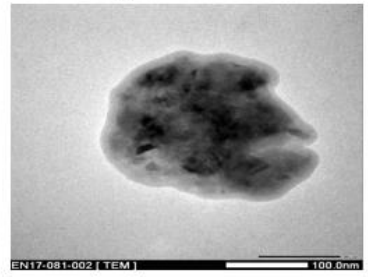

(d)

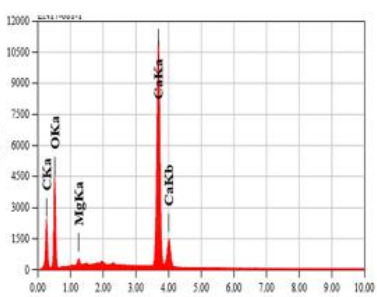

(f)

Figure 1. The SEM image of a $\mathrm{CaCO} / \mathrm{Ca}(\mathrm{OH})_{2}$ nanomaterial synthesized by the sol-gel method, (b) $\mathrm{CaCO} / \mathrm{CaCO}_{3}$ nanomaterial synthesized by thermal method, (c) of $\mathrm{CaCO} / \mathrm{Ca}(\mathrm{OH})_{2}$ from sol-gel method, (d) TEM image of $\mathrm{CaCO} / \mathrm{CaCO}_{3}$ synthesized by thermal method, (e) $\mathrm{EDS}$ of $\mathrm{CaCO} / \mathrm{Ca}(\mathrm{OH})_{2}$ nanomaterial synthesized from sol-gel method, and (f) Energy dispersive spectroscopy (EDS) nanomaterial synthesized by thermal method.

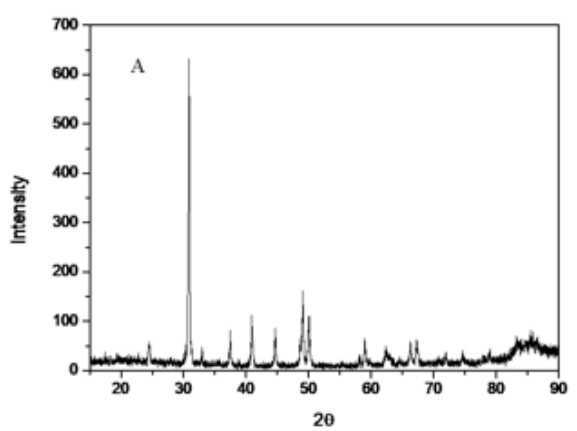

(a)

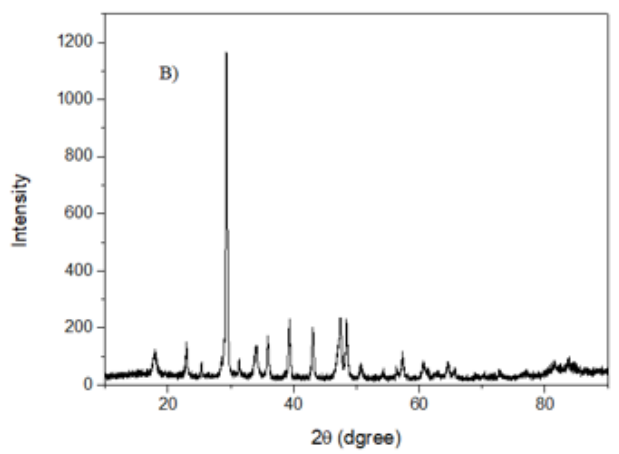

(b)

Figure 2. XRD pattern for: (a) Thermal method, (b) Sol-gel method.

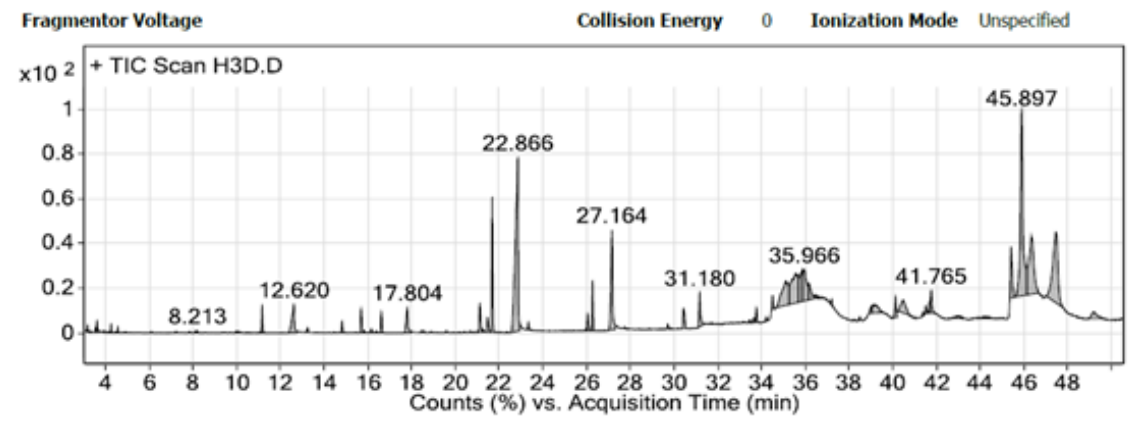

Figure 3. GC-MS for biodiesel produced using nanocatalyst prepared AT $900^{\circ} \mathrm{C}$ and ratio of 3:5.

\subsection{Biodiesel production.}

The generated nanocatalyst was then tested as a catalyst for biodiesel production as it was involved in the transesterification reaction. The biodiesel was finally separated from the unreacted species as depicted in Figure 3. 


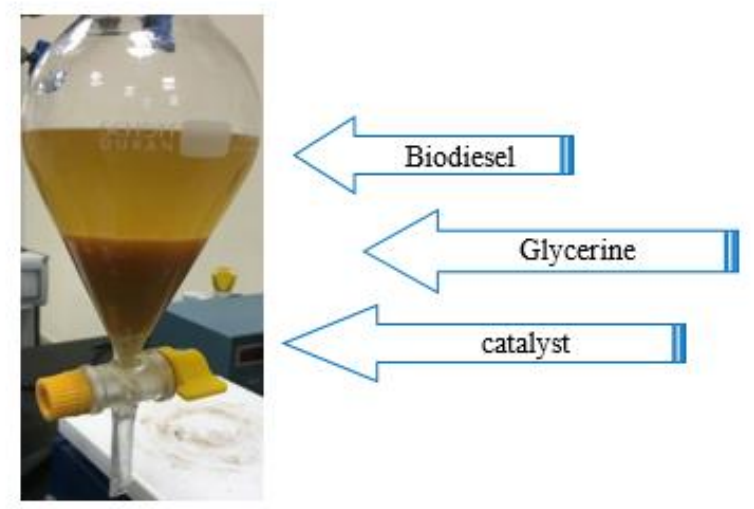

Figure 3. The separation of biodiesel product from other unreacted species and byproducts.

The nanomaterial was separated as well and kept to be used for a further transesterification reaction. The Calcite demonstrated very good reusability as the yield from calcite (sol-gel), and (thermal method) showed $81 \%$, and $88 \%$ respectively.

The biodiesel produced went under a NIR measurement to give enough identification of it. In order to generate a good signal to noise data, a derivative NIR spectroscopic measurement was conducted as shown in Figure $4 \mathrm{~A}$, and B. The implementation of $1 \mathrm{st}$ derivative functions with Savitzky-Golay smoothing to the spectra leads to improve the accuracy of the partial least square (PLS) models built, PLS model is evaluated based on parameters like RMSEC (Root Mean Square Error of Calibration), RMSEP (Root Mean Square Error of Prediction), as well as $\mathrm{R}^{2}$. The $\mathrm{R}^{2}$ is the correlation coefficient of determination, the RMSEC and RMSEP are used as an external indicator to check the predictive ability performance of the PLS regression models on the test set of samples [15]. In other words, they test the validity of the PLS model employed. All of these values are summarized in Table 1.

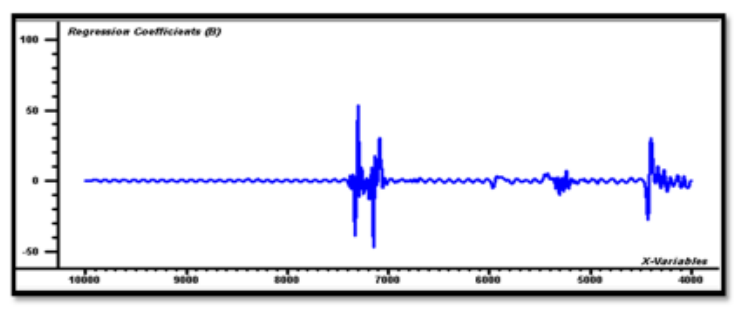

(a)

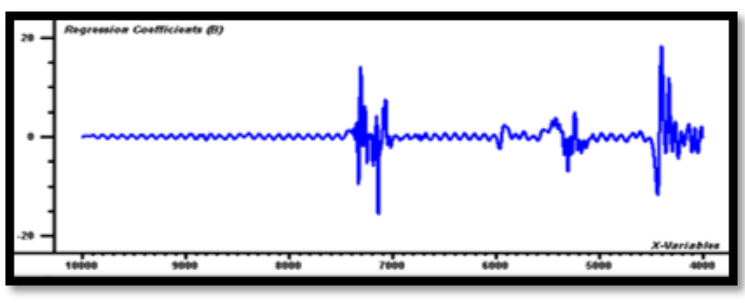

(b)

Figure 4. (a) The NIR spectra of biodiesel produced from using $\mathrm{CaO}$ (sol-gel) as a catalyst, and (b) is the NIR spectra of biodiesel produced from using the $\mathrm{CaO}$ (thermal method). In both figures the $\mathrm{x}$-axis represents the wave number (cm-1) and the $y$-axis is the absorbance baseline of the sample.

The data in the range of (4000-10000 cm-1) have been smoothed to enhance the signal to noise ratio. It can be seen from Table 1. that the smoothing via employing the first derivative spectra has reduced the RMSEC value from 0.25 to 0.19 . This reduction was associated with a 
promotion of the $\mathrm{R}^{2}$ from 0.95 to 0.97 . Based on these parameters, it can be concluded that the PLS model employed on these data is valid and of reasonable confidence.

A more statistical evaluation of data was obtained by harnessing the principal component analysis (PCA) and as depicted in Figure 5.

The PCA is another statistical procedure to account for the variability of any data set. The PCA score is plotted in Figure 5 showed a complete map of classification of pure diesel (standards) against various levels of dichloromethane adulterant in diesel. They were spaced and grouped in different regions of the PCA score plot based on the differences in their respective NIR spectra. In our case, the PCA demonstrated that the variation of data values observed was distributed in very small ranges, i.e. ( -0.6 to 0.6$)$ and ( -0.06 to 0.06$)$ which reveals that the standard deviation of the values is small.

Table 1. Statistical evaluation of data (R2, RMSEC, and RMSEP) of PLS model.

\begin{tabular}{l|c|l|c|l}
\hline \multirow{2}{*}{ Pre-processing } & \multicolumn{2}{|c|}{ PLS } & \multicolumn{2}{c}{ PLS } \\
\cline { 2 - 5 } & RMSEC & $\mathrm{R}^{2}$ & RMSEP & $\mathrm{R}^{2}$ \\
\hline Without pre-processing & 0.25 & 0.95 & 0.26 & 0.95 \\
\hline Baseline & 0.25 & 0.95 & 0.25 & 0.95 \\
\hline SNV & 0.24 & 0.96 & 0.26 & 0.95 \\
\hline $\begin{array}{l}\text { 1st derv. with 13 smoothing } \\
\text { points }\end{array}$ & 0.19 & 0.97 & 0.27 & 0.95 \\
\hline
\end{tabular}

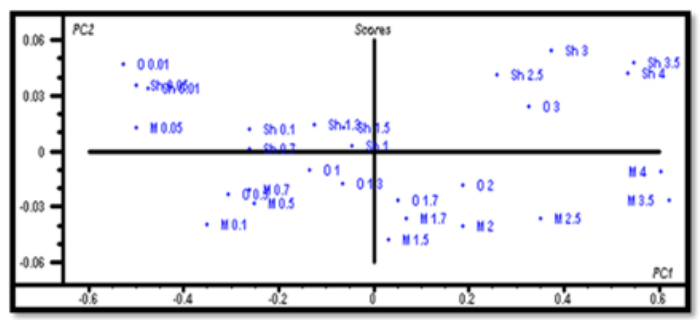

Figure 5. PCA score plot of pure diesel from different refinery against various levels of dichloromethane adulterant in diesel samples.

So far, we proved that the usage of $\mathrm{CaO}$ as a nanocatalyst demonstrated a very good capacity to turn the cooking oil waste into useful biodiesel to be used as a fossil fuel substitute. However, in order to say unambiguously that the produced biodiesel is efficient enough, we need to perform a test for its ignition efficiency or the delay time. The test was done by measuring what is so-called "cetane number' which measures the start of the injection of diesel to the start of the auto-ignition. In other words, the higher the number, the faster the autoignition. The cetane numbers for the produced biodiesels are summarized in Table 2.

Table 2. The cetane numbers of biodiesels generated by $\mathrm{CaO}$ nanocatalysts.

\begin{tabular}{l|c} 
Sample & Cetane number \\
$\mathrm{CaO}$ (sol-gel) + waste cook oil & 54 \\
\hline $\mathrm{CaO}$ (thermal) + waste cook oil & 51 \\
\hline $\mathrm{CaO}$ (sol-gel) reused + waste cook oil & 49 \\
\hline $\mathrm{CaO}$ (thermal)reused + waste cook oil & 54
\end{tabular}

It can be inferred from the data in Table 2 that the biodiesel produced showed a very good cetane number. These numbers are in fact indicative of efficient biodiesel. More importantly, the $\mathrm{CaO}$ (thermal method) was a very good choice as a catalyst based on its catalytic activity. 


\section{Conclusions}

In this effort, the $\mathrm{CaO}$ nanocatalyst showed a high catalytic activity especially the $\mathrm{CaO}$ synthesized via the thermal method. The robustness of the NIR first derivative and PLS-DA revealed a highly accurate determination of the biodiesel concentration. Additionally, a high yield of biodiesel produced even when the $\mathrm{CaO}$ nanocatalyst was reused. Most importantly, the high cetane number suggests using the biodiesel produced as an efficient fuel. Moreover, the $\mathrm{CaO}$ (thermal method) is basically produced from the egg shells which means it can be largely implemented as a green catalyst for generating a green diesel alternative for efficient performance in diesel powered engines.

\section{Funding}

This research received no external funding.

\section{Acknowledgments}

The authors extend their appreciation to the Department of Chemical and Petrochemical Engineering, College of Engineering and Architecture, University of Nizwa and to the Department of Chemistry, College of Science, Al-Nahrain University for continued support. Special thanks for DARIS research center (University of Nizwa) for the full cooperation. This research did not receive any specific grant from funding agencies in the public, commercial, or none profit sectors.

\section{Conflicts of Interest}

The authors declare no conflict of interest.

\section{References}

1. Luque, R.; Lovett, J.C.; Datta, B.; Clancy, J.; Campelo, J.M.; Romero, A.A. Biodiesel as feasible petrol fuel replacement: A multidisciplinary overview. Energy Environ. Sci. 2010, 3, 1706-1721, https://doi.org/10.1039/C0EE00085J.

2. Ganjehkaviri, A.; Mohd Jaafar, M.; Hosseini, S.; Musthafa, A. Performance Evaluation of Palm Oil-Based Biodiesel Combustion in an Oil Burner. Energies 2016, 9, 97, https://doi.org/10.3390/en9020097.

3. Vyas, A.P.; Verma, J.L.; Subrahmanyam, N. A review on FAME production processes. Fuel 2010, 89, 1-9, https://doi.org/10.1016/j.fuel.2009.08.014.

4. Khairul Azly Zahan 1,2 ID and Manabu Kano. Biodiesel Production from Palm Oil, Its By-Products, and Mill Effluent: A Review. Energies 2018, 11, 2132, https://doi.org/10.3390/en11082132.

5. Sylvia Adipah Introduction of Biodiesel as a Sustainable Resource. Journal of Environmental Science and Public Health 2019, 3, 99-103, https://doi.org/10.26502/jesph.96120050.

6. Union zur Förderung von Oel- und Proteinpflanzen e.V. The significance and perspective of biodiesel production - A European and global view. OCL 2019, 26, 1-8, https://doi.org/10.1051/ocl/2019042.

7. Dennis Y.C. Leung, Xuan Wu, Leung M.K.H. A review on biodiesel production using catalyzed transesterification. Appl. Energy 2010, 87, 1083-1095, https://doi.org/10.1016/j.apenergy.2009.10.006.

8. Taufiq-Yap, Y.H.; Lee, H.V. Higher Grade Biodiesel Production by Using Solid Heterogeneous Catalysts. In: Advances in Biofuels. Eds.; Springer: New York, NY, USA, 2013; pp. 153-176. https://doi.org/10.1007/978-1-4614-6249-1_10.

9. Anwar, M.; Rasul, M.G.; Ashwath, N.; Rahman, M. Optimization of Second-Generation Biodiesel Production from Australian Native Stone Fruit Oil Using Response Surface Method. Energies 2018, 11, 2566, https://doi.org/10.3390/en11102566.

10. Meng, X.; Yang, J.; Xu, X.; Zhang, L.; Nie, Q.; Xian, M. Biodiesel production from oleaginous microorganisms. Renew. Energy 2009, 34, 1-5, https://doi.org/10.1016/j.renene.2008.04.014. 
11. Bryan, R.M. Biodiesel production, properties and feedstocks. Vitro Cell. Dev. Biol. Plant 2009, 45, 229266, https://doi.org/10.1007/s11627-009-9204-z.

12. Van Gerpen J., Shanks B., Pruszko R., Clements D., Knothe G., Biodiesel production technology. National Renewable Energy Laboratory 2004.

13. Snežana, Ž.; Milan, V. Environmental impacts the of production and use of biodiesel. Environ Sci Pollut Res 2018, 25, 191-199, https://doi.org/10.1007/s11356-017-0649-z.

14. Plank, C.; Lorbeer, E. Simultaneous determination of glycerol, mono-, di-, and triglycerides in vegetable oil methyl esters by capillary gas chromatography. $J$ Chromatogr A 1995, 697, 461-468, https://doi.org/10.1016/0021-9673(94)00867-9.

15. Meher, C.; Vidya, D.; Naik, N. Technical aspects of Biodiesel production by transesterification: a review. Renew Sustain Energy Rev 2006, 10, 248-268, https://doi.org/10.1016/j.rser.2004.09.002.

16. Eryilmaz, T. Process optimization for biodiesel production from neutralized waste cooking oil and the effect of this biodiesel on engine performance. CT\&amp;F - Ciencia, Tecnología y Futuro 2018, 8, 121-127, http://doi.org/10.29047/01225383.99.

17. Ruhul, A.M.; Kalam, M.A.; Masjuki, H.H.; Fattah, I.M.R.; Reham, S.S.; Rashed, M.M. State of the art of biodiesel production processes: A review of the heterogeneous catalyst. RSC Adv. 2015, 5, 101023-101044.

18. Taufiq-Yap, Y.H.; Lee, H.V.; Hussein, M.Z.; Yunus, R. Calcium-based mixed oxide catalysts for methanolysis of Jatropha curcas oil to biodiesel. Biomass Bioenergy 2011, 35, 827-834, https://doi.org/10.1016/j.biombioe.2010.11.011.

19. Ullah, N.; Ullah, A.; Rasheed, S. Green synthesis of copper nanoparticles using extract of Dicliptera Roxburghiana, their characterization and photocatalytic activity against methylene blue degradation. Letters in Applied NanoBioscience 2020, 9, 897-901, https://doi.org/10.33263/LIANBS91.897901.

20. Kamel, D.A.; Farag, H.A.; Amin, N.K. et al. Utilization of Ficus carica leaves as a heterogeneous catalyst for production of biodiesel from waste cooking oil. Environ Sci Pollut Res 2019, 26, 32804-32814, https://doi.org/10.1007/s11356-019-06424-z.

21. Taufiq-Yap, Y.H.; Lee, H.V.; Yunus, R.; Juan, J.C. Transesterification of non-edible Jatropha curcas oil to biodiesel using binary $\mathrm{Ca}-\mathrm{Mg}$ mixed oxide catalyst: Effect of stoichiometric composition. Chem. Eng. J. 2011, 178, 342-347, https://doi.org/10.1016/j.cej.2011.10.019.

22. Madhuvilakku R.; Piraman S.; Biodiesel synthesis by TiO2-ZnO mixed oxide nanocatalyst catalyzed palm oil transesterification process, Bioresour Technol. 2013, 150, 55-9, https://doi.org/10.1016/j.biortech.2013.09.087.

23. Pandian, A.K.; Ramakrishnan, R.B.B.; Devarajan, Y. Emission analysis on the effect of nanoparticles on neat biodiesel in unmodified diesel engine. Environ Sci Pollut Res. 2017, 24, 23273-23278, https://doi.org/10.1007/s11356-017-9973-6.

24. Yuan, T.; Akochi-Koble, E.; Pinchuk, D.; Frederik, R.; Voort, V. FTIR On-line Monitoring of Biodiesel Transesterification. I.J. of Renew. Energy\& Biofuels 2014, 2014, 1-13, https://doi.org/10.5171/2014.178474.

25. Wen, Z.; Yu, X.; Tu S.; Yan, J.; Dahlquist, E. Biodiesel production from waste cooking oil catalyzed by TiO2-MgO mixed oxides. Bioresource Technology, 2010, 101, 9570-9576, https://doi.org/10.1016/j.biortech.2010.07.066.

26. Gurunathan, B.; Ravi, A. Process optimization and kinetics of biodiesel production from neem oil using copper doped zinc oxide heterogeneous nanocatalyst. Bioresource Technology 2015, 190, 424-428, https://doi.org/10.1016/j.biortech.2015.04.101.

27. Feyzi M.; Norouzi L. Preparation and kinetic study of magnetic $\mathrm{Ca} / \mathrm{Fe}_{3} \mathrm{O}_{4} @ \mathrm{SiO}_{2}$ nanocatalysts for biodiesel production. Renewable Energy 2016, 139, 1477-1478, https://doi.org/10.1016/j.renene.2016.03.086.

28. Narasaiah, B.P.; Mandal, B.K. Remediation of azo-dyes based toxicity by agro-waste cotton boll peels mediated palladium nanoparticles. Journal of Saudi Chemical Society 2020, 24, 267-281, https://doi.org/10.1016/j.jscs.2019.11.003.

29. Thangaraj, B.; Solomon, P.R.; Muniyandi, B.; Ranganathan, S.; Lin, L. Catalysis in biodiesel productiona review. Clean Energy 2018, 3, 2-23, http://doi.org/10.1093/ce/zky020.

30. Masato, K.; Jyu-suke, H. Transesterification of vegetable oil into biodiesel catalyzed by CaO: A review. Fuel 2012, 93, 1-12, https://doi.org/10.1016/j.fuel.2011.09.015.

31. Habte, L.; Shiferaw, N.; Mulatu, D.; Thenepalli, T.; Chilakala, R.; Ahn, W.J. Synthesis of Nano-Calcium Oxide from Waste Eggshell by Sol-Gel Method. Sustainability 2019, 11, 1-10, https://doi.org/10.3390/su11113196. 